\title{
How I Found My Way to the Written Word Through Visual Art
}

\author{
Laura Donkers \\ Isle of North Uist
}

\begin{abstract}
The author's practice-led research explores "the act of living." In order to advance this idea, the author has acquired skills in investigation and expresses her thinking through a descriptive and explanatory visual language. The author's learning journey, while not unique, has not been an ordinary one. Initial academic failure to achieve in the school education system contributed to her choosing a life working on the land and harbouring the belief that she was unable to learn academically. Still, the author has gained a rich base of physical knowledge and experience through the traditional oral route including learning interpersonal communication through body language and vocal tonality. The author has used this intuitive knowledge to develop an arts practice where she explores the bio-cultural links between people and the lands they inhabit, creating works that aim to extend knowing through emphasising the experience and atmosphere of landscape. At this time, when our lives have become increasingly encoded and intellectually based, the author shares a belief with American philosopher Eugene Gendlin (b. 1926) that the "felt sense” can be developed in order to enable us to engage more fully with the world around us. The author explores this idea in her visual art but also realizes the need to express it in writing, both in order to reach a wider public and because of the possibilities offered by the written word to make public which is private and held deep within.
\end{abstract}

Keywords: embodied thinking, primary observation, open work, fieldwork, drawing, interconnection, interaction, felt sense

As an environmental arts practitioner, I was often troubled by the work I made as I felt that I did not really know quite what it was about. I would work outside and respond intuitively to what I saw by making drawings, videos, and sculptural interventions. I would then wait to see what sort of reaction the work would get in the hope that the viewer would be able to tell me what they felt it was about, or at least what they might have taken from it. Of course, I did have my own ideas but I always felt they were elusive, enigmatic, and not really possible to pin down. I also had some doubts about their validity.

\section{A Learning Journey}

My learning journey, while not unique, has not been an ordinary one. Initial academic failure to achieve in the school education system contributed to my choosing a life working on the land and harbouring the belief that I was unable to learn academically.

I grew up in London's sprawling suburbia but left, aged eighteen, for the countryside of southwest England to restart my life in agriculture. Milking cows, driving tractors, helping to manage the land, every day presented a new discovery that taught me something about the fabric of life, but also that I could be good at

Laura Donkers, BA, MFA, Environmental Art Hebrides Ltd., Isle of North Uist, Outer Hebrides, UK; main research fields: Fine Art Practice relating to Embodied Cognition, Bio-Culturalism, and the Open Work. Email: laura.donkers.art@googlemail.com. 
something and enjoy seeing the immediate results of my labour "in action.” Learning how "to do" through developing fundamental life skills like learning how to listen, how to watch, how to evaluate, how to respond, and the importance of learning how to question, learning to trust in what your body can do.

In this modern era, to learn through the traditional oral route is a remarkable opportunity, providing a rich base of physical knowledge and experience, being taught through doing via the simile, symbol, metaphor, expression, imagery, and other forms of interpersonal communication that is expressed through body language and vocal tonality. Artistic practice is of course the refinement of all these skills.

The "finding of my way" really came together when I found myself on the Isle of North Uist, Outer Hebrides, where we settled when my husband took up his first job as the local veterinary surgeon. The opening up of a new art school, ${ }^{1}$ there some years later provided the opportunity to learn about art for the first time. I did not realize how all the intuitive knowledge I had acquired from earlier years would slowly develop into an arts practice of my own.

Uist is a special place. One of a collection of islands out to the west of Scotland: An open place on the edge of the Atlantic is populated by crofters and fisherman earning their living in traditional ways by modern standards. There is much that can be learned from people, who live their life by the seasons, experiencing successes and failures, succumbing to the elements, adapting their practices, and adapting their expectations to fit in with nature's systems. But it is still very much a place of the modern world that is affected by the strains that society is placing on the planet as a whole. Nowhere is immune, and it is folly to ignore the impact that is being felt in many similar edge-lands in the world right now. When you live in a place like this, you must live with the whole thing. There is no escaping it. It's a collection of rocks in the middle of the sea with a layer of soil on top, and upon that we make a life and so does all manner of other life. We are seamlessly interconnected, and therefore interdependent. When you realize that everything sits at the same level, as traditional land and sea-based communities do, you understand things horizontally rather than hierarchically. This subject matter underlies all of the work that I make.

\section{The Act of Living}

My practice-led research explores the "act of living" and how art can expand ways to reflect on and develop our lived experience. I express this in a descriptive and explanatory visual language through ideas that develop from drawing and photography, and eventually extend into video and sound installation. The key areas of context and output that my work centers on can be distilled into the collection and presentation of primary observations which interrogate the political, physical, and material conditions of landscape as experienced through the body. Forming around concerns, as our lives become increasingly encoded and intellectually based, there are less and less opportunities for us to directly connect with the places where we live. This work then, aims to trigger understanding of our connection to the whole act of living. However, in practice, I find that much seems to get lost in the translation from "fieldwork" to artwork, so the work is also about exploring the ambiguous space between language and its ability to communicate clearly or truthfully. In the opening lines of “Toward a Philosophy of the Act," Bakhtin wrote "Aesthetic activity... is powerless to take possession of that moment of being which is constituted by the transitiveness and open event-ness of being” (1993). ${ }^{2}$

In an effort to counter art's inability to capture this felt sense ${ }^{3}$ of reality, I create "open works" ${ }^{4}$ that employ the scientific and dialogical processes of field research. Methods such as interviewing, fieldwalking, and surveying via the photographed, videoed, and drawn, are in order to collect and present primary 
observations that are about the actualities of living the first hand in touch with environment, community, and self.

\section{Land Radius (2014) $)^{5}$}

From the perspective of the hunter's gaze: told through over 500-minute-long clips, via a Bushnell Trail Camera, Land Radius (2014) presents 60 days of activity on a small piece of North Uist's common land. A salt marsh, which hosts subtle and extraordinary colonies, such as Armeria Maritima's tufts of pink foam ${ }^{6}$, the red deer lurks and grazes moths, herons, otters, and gulls, tracking weather patterns, and the surge of the tide as it overwhelms the land at new moon. In counter, response to these activities is an audio track of testimonies. Told through human eyes, these are the stories of frustration at the unchecked increase in deer numbers, the protected status for marauding geese, and Land Raiding ${ }^{7}$ chronicles, that share the wisdom of experience of the naturalist and crofter, seafarer, and scientist. ${ }^{8}$

A site-specific intervention drawn on the land, the blue ring ${ }^{9}$ represents our separation from the natural and our unwillingness to connect with reality. The protective covering of "non-being" dominates our lived experience. We are the masters of all we survey, but the deception of the panorama is that the viewer is not contained within the viewed yet which is present all the same. From this panoptical position, the all-seeing watcher is concealed from himself.

\section{Gendlin's Theory on “The Body, Environment Interaction”}

"Your situation and you are not two things, as if the external things were a situation without you. Nor is your bodily sense separate from the situation and merely internal... the body-sense is the situation, inherently an interaction, not a mix of two things" (Eugene Gendlin 1992). ${ }^{10}$

Gendlin's theories help us to understand how we are grounded within the context of all that we see rather than perceiving it from a distance. He does this by identifying that we are interactions with our environments in the same way that plants are.

The plant is an interaction directly with its environment, without a perceptual datum in front of itself. Its body does not first exist and only then interact. Rather, its growth and life-processes consist of environmental interaction. And our bodies also consist of such environmental interaction processes (Eugene Gendlin, 343). ${ }^{11}$

When we perceive taste, touch, colours, smells, and sounds through our five sense organs, we can do that only because the body is doing the living in the first place-rather than it being the primary situation, as proposed by Maurice Merleau-Ponty in Primacy of Perception (1962), ${ }^{12}$ perception comes secondary to the primacy of responsive bodies which interact with the world through the creative flow of living: breathing, feeding, growing, walking, etc.. When we feel ourselves walking on the soft ground that sensation comes up through our bodies starting from our feet. We sense the stones that might trip us; the soggy peat land that might cause us to sink further than we would wish, but also the more stable ground that lets us walk faster, even run. Our bodies feel the hot tea as it trickles down our gullets; the cold air that causes us to gasp. We sense, too, the space behind us in a direct bodily sense rather than through hearing, vision, or touch.

"You sense behind you not just the space, nor just space-filling visible things. You sense behind you the people to whom you could turn and speak. Those people are part of your situation just now, and you sense them as part of your sense of the situation you are in” (Eugene Gendlin, 346). ${ }^{13}$ 
Gendlin progressed Merleau-Ponty's work, showing how an intricate "bodily sensed knowledge” emerges from our bodily interaction with the world. This bodily sense of our situation is present all the time. We know where we are, what we are doing, what we are going to do, and also the potential of those actions, but we largely do all of this without being consciously aware of it. Gendlin believes that there is much to be gained in experiencing a deeper connection in the world if we can first develop a greater awareness within ourselves. ${ }^{14}$

\section{Social Activation}

While past social activism has led to reforms that defended and achieved greater communal sharing of the benefits afforded by "progress" something has clearly gone awry, as the soul of our age seems now to be expressed through the primacy of individual privilege above community good, and at a cost that threatens our present and our future.

My work seeks to reexamine the practice of "social activation" by bringing experiences to the audience and bringing audiences into experiences. I construct works that activate response through a self-propelling format, itinerary, or scenario that I do not directly lead.

"Proposition for a Reading Group" 15 is a collective, public artwork that invites participants to play a simple child's card game called "Go Fish" using a text called "Monument", produced and printed in the form of a set of playing cards. The goal is to generate a reflective, shared experience through the playing out of a game of chance that may or may not lead to an understanding of the text.

The text, Monument, is an artist book. Specially created sets of playing cards containing 54 separate images and the text piece monument ${ }^{16}$. The text is intentionally fragmented into independent passages to be understood lyrically or narratively, as well as a whole, and to be read silently as well as out loud, while related images flash into view. Taking its title from the description of the Monkey-Puzzle Tree declared a natural monument in Chile in 1976 and symbol of colonialism (author's declaration), this text investigates the bio-cultural heredity of the Outer Hebrides through the riddle of how a Monkey-Puzzle Tree (Araucaria Araucana) came to be planted on a small island in Loch an Eilean, Askernish, Isle of South Uist, while, at the same time, the area was being forcefully depopulated through the brutal regime of the Highland Clearances. The images on the card backs present botanical photographs of all the plant species on the island taken during a research trip that I made there in 2012.

Parameters for the artwork are provided by rules of the game, expectation of role, and a familiarity with format. Caught up in the flow of a game, the player becomes absorbed in the processes and enjoyment of taking part. The format of the game is a convivial one but the intention is that it becomes a platform for dialogue as engagement with the text progresses. The anticipatory space between knowledge and format of delivery creates ambiguous space between language and its ability to communicate clearly or truthfully. The formal elements of the game provide the structure so that the receptive spaces that exist between the artwork and participants can flow freely enabling the players to engage with the underlying dynamic of the text and experience new perspective through reading, listening, and seeing.

This presentation was made through the restructuring the familiar book format in order to create open-endedness, and was influenced by Umberto Eco's text The Poetics of the Open Work. In this essay, he introduced composers and writers who had designed specific works to be played or read in an order that would be determined by the musician or reader and thereby present the endless opportunities for the work to be formed, interpreted and experienced, expanding the audiences capacity to engage with the work. 
These limitless combinations reveal the extensiveness and openness of our minds to consider and progress possibilities, yet this ability has also contributed to our current ecological and sociological dilemmas in the pursuit of the perfect solution, aspiring to better those who went before. Yet that goal remains ever elusive, and more and more wasteful, as we shed the unwanted materials of our "progress:" All those things that now lie discarded at our feet, challenging the purpose of continual effort where as you come to know more, so you discover how much there still is to be learned.

\section{Landship (2014)}

The final work I want to share with you is a temporary public art piece that was installed on Magdalen Green for the summer of 2014. This green has the distinction of being Dundee's oldest public park having been in use for some 400 years. "Landship" is a site-specific installation compring a five-meter diameter blue ring made of Polyethylene water pipe, which has been printed on the inside curve with a text that I composed. The drawing delineates an area of "common land" within a much loved area of public space in Dundee. The general public was encouraged to enter the sculpture area to read the text, and observe what grew within the space as the grass sward was left uncut. This sculptural piece was intended as a contemplation on the separateness of ourselves from the natural, but also, due to the safe and colourful material and circular form, was something fun for children to engage with, as a portal to jump into, create games with and imagine.

"Land Radius" and "Landship" delineate areas of common land in distinctly different settings, forming a complex, cumulative artwork that expresses the individual identity of each site, both claimed by human presence. These works interrogate the political, physical, and material conditions of landscape as experienced through the body, aiming to trigger an understanding of wholeness and present experiences of living the first hand, in touch with our environment, our communities and ourselves.

The text on the inside curve reads as follows:

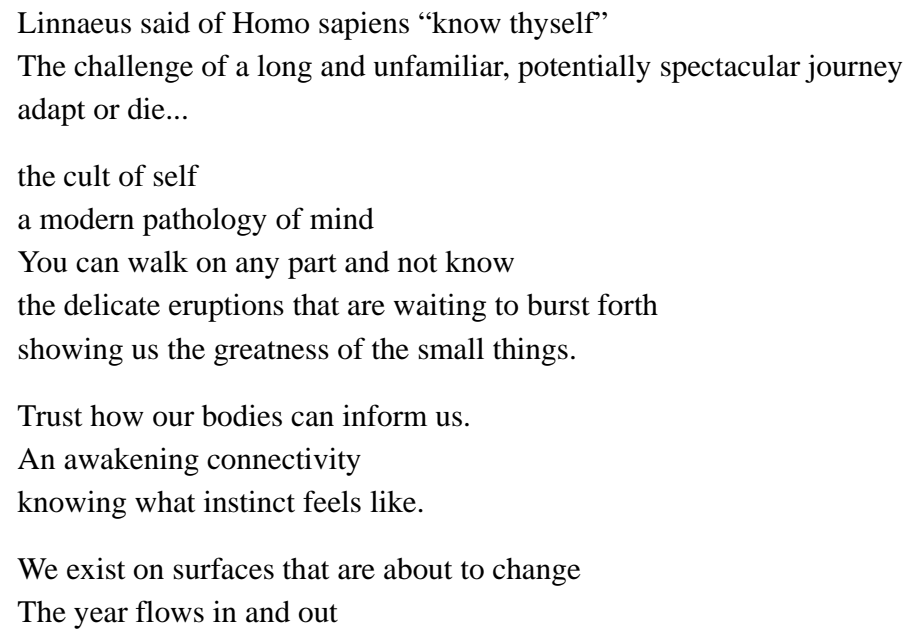

\section{Notes}

1. Taigh Chearsabhagh Museum and Art Centre, Lochmaddy, Isle of North Uist, Outer Hebrides, UK.

2. Bakhtin, M. M., Liapunov, V. (Trans., Ed.), Holquist, M. (Ed.) (1993) Toward a Philosophy of the Act, University of Texas Press, Austin, USA. 
3. See Embodied Situated Cognition: <http://www.embodiment.org.uk/topics/felt_sense.htm>.

4. Term used as defined by Umberto Eco in The Open Work (1989).

5. Multimedial piece comprising video/sound/publication/screen print available to view at www.earthebrides.com.

6. Armeria Maritima, commonly known as Sea Pinks, colonisers of salt marsh throughout Britain. The subject of many studies into hyper accumulator plants for their ability to extract heavy metals from the soil. See article: Recovery of salt marsh in Brittany sixteen months after heavy pollution: <http://www.sciencedirect.com/science/article/pii/0013932770900170>.

7. The stories of the landless to gain tenancy rights: <http://www.crofting.scotland.gov.uk/>.

8. Land Radius Fugue-Transcription of Dialogues: <http://www.blurb.co.uk/b/5483733-land-radius>.

9. Drawing material: 30m length blue Polyethylene water pipe.

10. Gendlin, E. T. (1992). “The Primacy of the Body, not the Primacy of Perception.” Man and World, 25(3-4), 341-353: $<$ http://www.focusing.org/gendlin/docs/gol_2220.html>.p. 347.

11. Gendlin, E. T., ibid., p. 343.

12. Merleau-Ponty, M. Primacy of Perception (1962), translated by Edie, J. M. (ed.) (1964). Maurice Merleau-Ponty, The Primacy of Perception and Other Essays on Phenomenological Psychology, the Philosophy of Art, History and Politics. USA: Northwestern University Press.

13. Gendlin, E. T., ibid., p. 346.

14. How to Think at the Edge, The Focusing Institute: <http://www.focusing.org/tae-intro.html>.

15. Proposition for a Reading Group: <https://vimeo.com/94789540>.

16. Text available to read: <http://earthebrides.com/page27.htm>.

\section{Works Cited}

Bakhtin, Mikhail Mikhailovich, Liapunov, Vadim (Trans., Ed.), Holquist, Michael (Ed.). Toward a Philosophy of the Act. Austin, USA: University of Texas Press, 1993.

Eco, Umberto. The Open Work. Trans., Anna Cancogni. Cambridge: Harvard University Press, 1989.

Gendlin, Eugene. "The Primacy of the Body, not the Primacy of Perception." Man and World 25 (3-4), 341-53. $<$ http://www.focusing.org/gendlin/docs/gol_2220.html >. 1992, 347.

Merleau-Ponty, Maurice. Primacy of Perception, trans., Edie, J. M. (ed.) (1964). Maurice Merleau-Ponty The Primacy of Perception And Other Essays on Phenomenological Psychology, the Philosophy of Art, History and Politics. USA: Northwestern University Press, 1962.

Embodied Situated Cognition. <http://www.embodiment.org.uk/topics/felt_sense.htm>.

Recovery of salt marsh in Brittany sixteen months after heavy pollution. $<$ http://www.sciencedirect.com/science/article/pii/0013932770900170 >.

Land Raids. <http://www.crofting.scotland.gov.uk/ >.

How to Think at the Edge, The Focusing Institute. <http://www.focusing.org/tae-intro.html>. 